66

\title{
2nafreong Dden.
}

********************

\section{XXVI. \\ IUtud) auf fitd felbit.}

Geigt 3act)us ins sebirne,

Eo (j)lummern alle Sorgen,

Und fang idh an zu fingen,

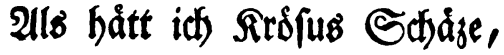

Und lieg auf zarten Myrten,

Betrånąt mit grůnem Epheu,

Und fehe mit Jeractitung

Die Şelt zu meinen Š̃oen.

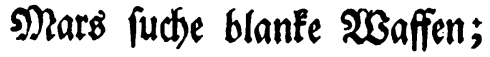

Sth fucthe volle Becther.

Sieich, Snabe, reich mir einen!

Ez ift ja zefummal beffer

Beraufdt), als leblos liegen.

uno rebe mit Deraditung ote Delt 34 meto nen fứren.]

Heureux, qui méprifant l'opinion commune,

Que notre vanité peut feule autorifer,

Croit, comme moi, que c'eft avoir fait fa fortune,

Que d'aroir, comme moi, bien fçu la móprifer!

XXVII. MBies 